\title{
Interferência cultural: ativismo, mídia e arte
}

\section{Marcus Antônio Assis Lima}

\section{Resumo}

Este artigo procura discutir um gênero de ativismo nas novas mídias, a interferência cultural, estabelecendo as principais características dessa prática de ativismo. Procuramos, ainda, apontar como a interferência cultural não se restringe à crítica ao consumismo ou reelaborações da publicidade, mas como ela vem sendo utilizada também no campo da arte, especialmente na interface dessa com a política e a cultura popular.

\section{Palavras-Chave}

Ativismo. Novas mídias. Interferência cultural. Ativismo.
Marcus Antônio Assis Lima | malima@uesb.edu.br Doutor em Estudos Linguísticos pela Universidade Federal de Minas Gerais - UFMG. Professor do Programa de Pós-Graduação em Letras: Cultura, Educação e Linguagens - UESB.

\section{Ativismo nas novas mídias}

0 fenômeno das novas mídias tem levantado um debate intenso no campo dos direitos humanos sobre se 0 ativismo que daí surgiu tem algum impacto na luta contra os abusos dos direitos humanos ou se esse ativismo deve ser pensado apenas em termos de um "sentir-se-bemclicando". Petições on-line, por exemplo, veem há muito tempo sendo utilizadas para fazer as pessoas tomarem consciência de algo e também para suscitar uma ação individual - "por favor, assine esta petição" - que signifique alguma mudança politica. As petições são um meio popular de ativismo por direitos humanos na época da internet, especialmente por intermédio das redes sociais, "[...] onde as assinaturas são coletadas eletronicamente ou através do clique do mouse, ao contrário da fórmula fora de moda de se coletá-las fisicamente" (BORER, 2012, p. 151). "A internet está criando 0 alicerce e possibilitando 0 surgimento de movimentos contrários à guerra e a favor da paz e da justiça social, /.../ sem paralelo ao redor do mundo", argumentam Richard Kahn e Douglas Kellner (2004, p. 88). 
Entretanto, as novas mídias não são, como às vezes elas têm sido retratadas, um "pó mágico", feito de pixels, que pode ser espalhado sobre problemas complexos para fazê-los melhores, mas elas são o começo de um impacto no ativismo que vai além do "curtir" e dos tweets. 0 fato é que as novas mídias estão tornando possíveis para os indivíduos certos aspectos do ativismo que antes estavam restritos apenas aos membros de organizações centralizadas. "Elas não causam revoluções, mas elas estão revolucionando o modo como os ativistas podem iniciar uma", afirma Sarah Kessler (2012, p. 205). 0 impacto das novas mídias no ativismo deve, assim, ser visto não apenas pela ótica de pessoas envolvidas casualmente ou de ações de baixo custo. Essas redes também estão contribuindo para o modo como os movimentos são organizados, ou seja, elas estão definindo um novo modo de como os ativistas se aproximam desses movimentos, ao darem poder a um coletivo ${ }^{1}$ de pessoas de levar adiante suas tarefas como ativistas de uma maneira historicamente diferente da que sempre foi, quando as comparamos às formas tradicionais de ativismo, dominadas por organizações centralizadas (KESSLER, 2012, p. 213).

Entender as relações entre as novas mídias e 0 ativismo, nesse inicio do século XXI, requer, então, um conhecimento mais amplo sobre os vários modos nos quais os fluxos e forças sociais, econômicas e produtivas operam dentro do domínio midiático atual. 0 certo é que a proliferação de conexões via computadores tem resultado em novas formas de engajamento e ativismo por parte dos cidadãos, facilitando 0 questionamento da legitimidade de variadas formas de governo ao redor do mundo, embora, é necessário termos claro, que realizações tecnológicas sozinhas não são suficientes para causarem mudança social e 0 aperfeiçoamento das condições de vida ao redor do globo, pois as "tecnologias podem ser implantadas facilmente tanto para garantir quanto para negar acesso" (COOPER; TURCOTTE, 2012, p. 182).

Como qualquer nova mídia, entretanto, 0 potencial das mídias sociais ainda não foi totalmente alcançado e seus usos ainda estão para serem descobertos. Mas é fato que "as mídias sociais tornaram mais fácil para as pessoas se alinharem publicamente a alguma causa: não há mais necessidade de panfletos impressos, cartas ou adesivos nos automóveis" (KESSLER, 2012, p. 207). "A mídia social é uma forma trans-demográfica e trans-geracional que eu tenho para me alinhar publicamente com uma causa", revela Aaron Sherinian (apud KESSLER, 2012, p. 206), diretor executivo de Comunicação da United Nations Foundation. "No passado, eu teria que sair como 'homemsanduíche' pelas ruas para dizer de maneira 
aleatória às pessoas que eu me importava com 0 meio ambiente, com crianças ou com a saúde".

0 que queremos salientar é que 0 baixo custo de se alinhar publicamente a alguma causa e a facilidade de distribuição por "laços fracos" fazem as novas mídias tão efetivas, senão mais efetivas, que campanhas institucionais nas mídias tradicionais, e a habilidade dos indivíduos de se autopublicarem elevam nível mundial a visibilidade de alguns movimentos que talvez eles nunca fossem capazes de alcançar. Isso porque uma organização - ou um indivíduo - pode utilizar ferramentas de compartilhamento social para colocar o ônus da distribuição de petições, cartas ou um boicote a cargo de um coletivo descentralizado de indivíduos. ${ }^{2}$ Assim, quanto mais pessoas engajam casualmente em uma causa, mais oportunidades haverá para engajar os indivíduos que passaram essa primeira etapa, ou seja, ações despretensiosas, como assinar uma petição on-line, podem, teoricamente, ser uma "porta de entrada" para o engajamento mais profundo. Dessa maneira, os indivíduos que espalham mensagens e realizam atividades de ativismo através das novas mídias estão, de certa maneira, sendo recrutados por algum movimento. Assim, um indivíduo, mantendo o seu nível de envolvimento constante, pode contribuir mais para os objetivos do ativismo, usando novas mídias, do que ele poderia sem elas.

\section{Gêneros de ativismo nas novas mídias}

Tendo definindo o que entendemos por novas mídias, precisamos, agora, clarear o que estamos chamando de "novas mídias ativistas ou alternativas". Na última década, muitos pesquisadores exploraram os usos das mídia, incluindo as novas mídias e as tecnologias de informação nos movimentos sociais, políticos e culturais. John Downing (2008), por exemplo, notou que esses trabalhos representaram uma ruptura com a visão mais tradicional, que focava nos usos das tecnologias de comunicação, especialmente os meios de comunicação de massa, pelos partidos e nas campanhas políticas, por uma ênfase no engajamento dos cidadãos, dos ativistas ou das comunidades em questões e movimentos com a internet e tecnologias relacionadas (veja, ainda, Silver, 2003). Outros autores focaram naquilo que é chamado de "mídia tática", que seria uma resposta à queda do comunismo na Europa nos anos 1980, ao fracasso dos movimentos revolucionários de esquerda e a ostensiva "vitória" do capitalismo. Os teóricos dessa visão, especialmente Geert Lovink e 
David Garcia (1997), argumentavam que face à fragmentação cultural e a subjetividade radical da pós-modernidade, a única maneira viável de ativismo político seriam movimentos pequenos, esporádicos, nômades e de rápida resposta, não revolucionários, mas de "resistência".

Genericamente falando, os analistas tratavam os projetos nas novas mídias alternativas e ativistas como a última encarnação de uma longa linha histórica de oposição por intermédio de mídias radicais, anarquistas ou underground, incluindo jornais impressos, pequenas publicações, rádios piratas e vídeos de acesso público, salientando o experimentalismo, a baixa qualidade, a diversidade de pontos de vista e valores, o ecletismo e subculturalismo de suas audiências, 0 amadorismo e a natureza voluntária da participação e a marginalidade desses projetos em oposição ao alcance das instituições midiáticas (ATTON, 2002; DOWNING et al., 2001; MCCAUGHEY; AYERS, 2003; MEIKLE, 2002; VEGH, 2003). Sandra Brahan (2002), por exemplo, identificou quatro características das mídias alternativas que poderiam ser aplicadas às mídias táticas; " 0 uso dos meios como conteúdo, a rejeição da ideologia, a emergência da política e das artes e a crença da habilidade digital para fazer as coisas acontecerem mais rapidamente".

Entretanto, muitos poucos desses pesquisadores tentaram definir o que distinguiria os projetos alternativos envolvendo mídias tradicionais daqueles que utilizam a variedade de novas mídias. Alguns usaram conceitos das pesquisas clássicas em comunicação de massas (a teoria dos usos e gratificações, por exemplo) ou dos media studies (a tríade produção, texto e audiência para os casos envolvendo as novas mídias. Um dos poucos que tentaram estabelecer alguma distinção foi Chris Atton (2004), cuja análise minuciosa tanto das mídias alternativas tradicionais e da "internet alternativa" ressaltou as diferenças entre os projetos alternativos daqueles mainstream. Ele sugeriu que, ao longo do tempo, as mídias alternativas vêm buscando ser participativas, emancipatórias, não-comerciais, autênticas - isto é, crente nos pontos de vista ou experiências das comunidades e anti-institucionais. Segundo ele, elas combinam tanto "uma expressividade criativa quanto uma responsabilidade social" (ATTON, 2002, p. 13-14) de uma maneira que as distancia das mídias alternativas tradicionais. Dessa maneira, ele define a internet alternativa como "[...] um conjunto de projetos, intervenções e redes midiáticas que procuram desenvolver formas diferentes de se 'fazer' a mídia, em oposição aos moldes esperados e geralmente mais aceitos" (ATTON, 2004).

Inspirando-se nos trabalhos de Atton, Lievrouw (2011, p.19) propõe definir as novas mídias alternativas e ativistas salientando que elas "empregam ou modificam artefatos comunicacionais, práticas e arranjos sociais das tecnologias de informação e comunicação de maneira a desafiar ou modificar os modos esperados ou aceitos de se fazer a sociedade, a 
cultura e a política". Para ela, as mídias alternativas e ativistas não apenas refletem sobre ou criticam a mídia tradicional e a cultura, mas, especialmente, elas constituem ou intervêm sobre elas.

Tendo isso em vista, Leah Lievrouw $(2011,2012)$ busca empreender uma taxonomia dos projetos ativistas ou alternativos nas novas mídias por intermédio de uma classificação desses projetos em cinco grandes gêneros: interferência cultural (cultural jamming), computação alternativa (alternative computer), jornalismo participativo (participatory journalism), mobilização mediada (mediated mobilization) e conhecimento compartilhado (commons knowledge). Segundo ela, cada um desses gêneros fazem referência a diferentes domínios da vida social, da cultura ou das práticas tecnológicas. Por exemplo, a interferência cultural toma de empréstimo, comenta ou subverte elementos da cultura popular, tais como o entretenimento, a publicidade, as artes, a literatura, o cinema. A computação alternativa simultaneamente critica e reconfigura a infraestrutura das tecnologias da informação e comunicação. Projetos de jornalismo participativo empregam práticas e éticas profissionais de reportagem e opinião editorial para cobrir comunidades, acontecimentos e pontos de vista que são rejeitados pela grande imprensa. As mobilizações mediadas expandem e ativam o poder do "ao vivo", das organizações e relações sociais locais. Projetos de conhecimento compartilhado reorganizam e categorizam as informações de modos a desafiar ou reenquadrar os conhecimentos especialistas das disciplinas e instituições culturais tradicionais (LIEVROUW, 2011).

Julgamos pertinente uma breve abordagem sobre a noção de "gêneros", tendo em vista a enorme polêmica que se costuma travar em relação a esse conceito. De início, o conceito de "gênero" possui uma longa história, não apenas nas Ciências da Comunicação, diga-se de passagem, desde a classificação aristotélica dos diferentes tipos retóricos e do poder que eles exercem para influenciar ou persuadir as audiências, passando pela análise das principais formas literárias como a poesia e a ficção, até a categorização de filmes e programas de televisão de acordo com os estilos, formatos e conteúdos por exemplo, filmes de ação, faroeste, noticiários, talkshows etc.

Basicamente, um gênero é um tipo de expressão ou comunicação que é útil e/ou significativo dentre os membros de uma dada comunidade ou em uma situação em particular. Os gêneros possuem tanto uma forma quanto um objetivo, isto é, eles têm determinado formato material ou seguem determinadas formas convencionadas e eles permitem às pessoas se expressarem apropriadamente em dada situação. Apesar das características dos gêneros dependerem, em grande medida, das tecnologias de comunicação ou dos meios que são utilizados para produzilos, gênero e meio não são a mesma coisa - geralmente um gênero pode ser original de um meio e daí ser transportado para outros 
meios. 0s gêneros possuem muitas outras importantes características que são relevantes para os projetos de mídia alternativa ou ativista. Primeiro, eles ajudam a "mediar" ou facilitar a comunicação entre membros de uma comunidade. Para Phil Agre (1998, p.81), os gêneros são "0 entroncamento entre processos de produção de materiais midiáticos e os modos de utilizá-los". Denis McQuail (2005, p. 370) observou que

um gênero pode ser considerado como um dispositivo prático para auxiliar qualquer meio de comunicação de massa a produzir de maneira consistente e eficaz de modo a relacionar essa produção às expectativas da audiência /.../ um mecanismo de ordenação das relações entre os produtores e os consumidores.

Em segundo lugar, os gêneros são uma maneira de criar e manter contextos sociais e comunitários bem como os produtos culturais dessas comunidades e contextos. Eles também podem ser tão específicos para a visão de mundo de certos grupos que os outsiders podem não entendê-los; assim, os gêneros podem também agir como fronteiras ou marcas que excluem os outsiders ao mesmo tempo que reforçam os laços de pertencimento (HEBDRIGE, 1979), ou, como sugeriu Sonia Livingstone (1990, p. 155), "diferentes gêneros são concebidos para estabelecer diferentes visões de mundo". De fato, "o reconhecimento de um gênero em particular é um sinal de nosso pertencimento a uma comunidade em particular", afirmam Crowston e Williams (2000, p. 203). Finalmente, um ponto importante em relação aos gêneros é que eles não são fixos ou estáticos, mas ativos, modos dinâmicos de comunicação e expressão que se modificam conforme as circunstâncias e os interesses dos usuários.

\section{A interferência cultural}

0 quê exatamente é a interferência cultural? A interferência cultural é um conceito que pode facilmente se aplicado a uma enorme variedade de mídias, para além daquelas relacionadas à publicidade. A manifestação mais comum de interferência cultural é a transgressão publicitária um exemplo que normalmente é tomado como sinônimo para essas interferências. Mas a interferência cultural é melhor compreendida como um fenômeno mais amplo que simplesmente retrabalhar publicidades de modo a tornálas mensagens anticonsumo. A interferência cultural é um ótimo índice para os modos como os desenvolvimentos nas tecnologias da comunicação estão possibilitando uma ruptura entre os produtores e os consumidores. De acordo com Negativland (1995, p. 251), a interferência acontece "[...] quando a população bombardeada pela mídia eletrônica alcança um software que a encoraja a capturá-la". É útil, aqui, o trabalho de Henry Jenkins (2003, p. 286), ao mostrar como qualquer um pode participar "[...] adquirindo, comentando, apropriando, transformando e replicando os conteúdos midiáticos".

Esse gênero elabora uma crítica da cultura popular e mainstream, especialmente 0 capitalismo 
corporativo, 0 comercialismo e 0 consumismo.

Nele, os artistas e ativistas midiáticos apropriamse e reconfiguram elementos da cultura popular criando novos trabalhos de um ponto de vista irônico ou subversivo; dito de outra maneira, a interferência cultural "mina" a cultura mainstream para criticá-la. Como forma de produção artística e política, a interferência cultural remonta ao dadaísmo e os primeiros projetos de interferência cultural tomavam emprestado elementos dos meios de comunicação de massa e fontes da cultura popular, especialmente cartazes e imagens corporativas (p.ex., logotipos, slogans e produtos). Entretanto, com o surgimento da rede mundial de computadores, essas mesmas estratégias foram adotadas por ativistas on-line e artistas gráficos nos anos 1990, incluindo o lançamento de "memes" e 0 chamado "marketing de guerrilha" ou "viral".

0 termo teria sido cunhado por Mark Dery, artista de São Francisco, nos Estados Unidos, em 1984, para descrever a "[...] alteração em cartazes e outras artes underground que procuram iluminar o lado escuro da era dos computadores" (DERY, 1990). Ele define a interferência cultural como "[...] recorte midiático, guerrilha informacional, arte terrorista e guerrilha semiótica, tudo em uma coisa só" (DERY, 1993). Assim, a interferência cultural captura e subverte as imagens e as ideias da cultura da mídia tradicional para estabelecer um ponto crítico, ou seja, como gênero de ativismo nas novas mídias, a interferência cultural toma "[...] a forma da cultura popular com o propósito de subverter e criticar essa cultura"

(LIEVROUW, 2011, p.73, grifo do autor).

0 projeto de interferência cultural de engajamento com imagens da mídia por meio de técnicas da própria mídia, de modo a chamar a atenção para algo que de outra maneira não seria percebido, está diretamente relacionado às posições teóricas do Situationist International (DEBORD, 1987; MARCUS, 1989, entre outros). Esse grupo de intelectuais, escritores e artistas, ativos entre meados dos anos 1950 até 0 início dos anos 1970, procuravam minar aquilo que 0 principal teórico desse movimento, Guy Debord (1987, seção 1), chamou de "espetáculo": 0 espaço cultural integrado e comercializado no qual "[...] tudo que está vivo tornou-se uma representação". Esse grupo teve uma influência significativa nas revoltas de Paris em maio de 1968, quando a France-Soir (apud KNABB, 1981, p. 385) noticiou que os estudantes estavam "[...] lutando contra a publicidade fazendo uso dela e de suas armas". Uma dessas armas era a prática do détournement,${ }^{3}$ isto é, retirar uma imagem de seu contexto original e recontextualizá-la, criando uma síntese que chama a atenção tanto para 0 contexto original quanto para o novo significado. "Qualquer signo ou palavra está suscetível a ser convertido em algo mais, mesmo que seu oposto", sugeriram Debord e Wolman (1981, p. 13). Para Greil Marcus (1989, p. 179) détournement é "[...] a 
política da subversão da citação, cortando as cordas vocais de todo orador poderoso".

Enquanto muitos podem se ver tentados a identificarem isso com o surgimento da internet, Jenkins traça raízes mais profundas: as fotocopiadoras, cuja apropriação por pequenos jornais, mídias corporativas alternativas e produtores de fanzines possibilitaram uma ampliação de expressões subculturais; os reprodutores e gravadores de videocassetes, que permitiram às audiências a exploração de materiais de emissão, construindo bibliotecas pessoais e editando suas próprias produções amadoras; as filmadoras do tipo "camcorder", que permitiram aos amadores criarem sequências para produção de documentários; os vídeo games, que propiciaram uma sensação de imersão, participação e engajamento com narrativas da mídia; e as câmeras digitais e os softwares de edição de imagens, que, assim como os programas de edição de música, tornaram possíveis outras formas de produção (JENKINS, 2003, p. 286).

A interferência cultural retrabalha imagens e formatos preexistentes na mídia de modo a fazer uma afirmação política ou cultural. Mas, qual tipo de afirmação? No geral, a interferência é um ativismo autorreflexivo na mídia, tendo em vista que ela utiliza a mídia para chamar a atenção para um tópico da mídia, como a influência da publicidade, para ficarmos no uso mais difundido. E, normalmente, para chamar a atenção da mídia para esse tópico. Podemos resumir isso dizendo que a interferência cultural é uma prática que pega imagens familiares e os transformam em pontos de interrogação.

Muitos dos projetos de interferência cultural reconfiguravam imagens comerciais e espaços públicos, especialmente outdoors e outras publicidades, embora outras mídias impressas também fosse alvo desses projetos. De certo é que as possibilidades para a interferência cultural, como uma estratégia alternativa e ativista, foram tão diversas quanto eram as mensagens e as tecnologias disponíveis. Uma forma de interferência cultural de "contraespionagem" emergiu como uma resposta política ao crescimento do uso de Câmaras de Vigilância de Circuito Fechado (CCTV) tanto em propriedades privadas quanto em espaços públicos (MONAHAN, 2006). Grupos experimentais e de paródia dançavam em frente a câmaras de vigilância nos caixas eletrônicos (MARKOFF, 2002). Um projeto usava focos de raio laser como forma de dificultar o reconhecimento pelas câmeras em locais públicos (NAIMARK, 2002), recurso utilizado nas manifestações recentes no Brasil contra os âncoras de um dos mais assistidos e criticados telejornais pelos ativistas. Nos anos 1990, a interferência cultural tornou-se uma tática familiar entre os ativistas da mídia e foi amplamente estudada por acadêmicos (CARDUCCI, 2006; HAROLD, 2004; WETTERGREN, 2009). Entretanto, ela entrou em uma fase mais vigorosa e nova com a introdução da rede mundial de computadores e as tecnologias de navegação virtual. Atualmente, 
ela é uma tática central na comunicação

política e também na arte, mas, como

estratégia e estilo comunicacional para atrair

a atenção, ela também se tornou um elemento

estandardizado da cultura popular.

A interferência cultural é um tipo de ativismo na mídia que vai além das fronteiras da internet e apresenta como características principais:

a) 0 uso da ironia nas questões e atividades que ela critica; b) acontece em pequena escala, isto é, normalmente produzida por poucas pessoas e com poucos recursos financeiros; c) é essencialmente intervencionista, de modo a salientar, nas práticas e representações culturais e políticas que são seu alvo, as contradições e hipocrisias delas; d) exige uma "competência cultural" (LIEVROUW, 2011, p. 95), ou seja, a capacidade de reconhecer as convenções e clichês, símbolos e lógicas empregados; e) é nitidamente colaborativa, exigindo não apenas um esforço conjunto de seus criadores, 0 que pode ser chamado de "metacolaboração" (LIEVROUW, 2011, p. 95); f) a interferência cultural é, ainda, heterotópica, no sentido que ela cria espaços alternativos e oportunidades distintas de se perceber a cultura por um novo ponto de vista; g) sua transitoriedade pois, normalmente, são intervenções focadas em uma prática ou representação específica. Entretanto, algumas interferências culturais podem ganhar ares de "arte" quando são incorporadas por coleções privadas ou públicas de galerias ou museus.
Entretanto, a interferência cultural corre o risco de se tornar vítima de seu próprio sucesso, a partir do momento que suas táticas, aproximações e propósitos podem ser incorporados e aplicados tanto nas culturas alternativas quanto nas mais tradicionais formas de expressão.

\section{$4 \mathrm{~A}$ arte ativista}

Quando Rosemary Segurado (2007, p. 41)

diz que "[...] as formas de expressão da arte e da política na contemporaneidade se misturam e se ativam", não parece gratuito que a autora tenha escolhido a expressão "se ativam”. Torna-se latente, neste tipo de arte, 0 senso da resistência, traduzido em ações que complementam o discurso do artista ativista. Chaia (2007, p. 38-39), dessa forma, propõe 0 termo "arte radical contemporânea".

A arte radical contemporânea configura-se como uma prática crítica da sociedade, concretizando provocações e sabotagens contra o sistema capitalista ou tornando artísticas as intervenções sociais que imprimem novos significados às atividades coletivas e à vida social de pequenas parcelas da população. Esta diversidade de caminhos para a transformação social realiza-se através de atitudes contestatórias e ações autônomas - que se desenvolvem num espaço democrático, aberto, heterogêneo e segmentado. Neste processo, importa a presença do artista para transgredir e resistir, seja ele visionário, rebelde ou revolucionário, na luta contra a sujeição cultural, utilizando-se do esforço individual ou da cooperação coletiva, dos meios eletrônicos ou do correio, do conceito ou da materialidade, dos suportes tradicionais ou de novas tecnologias. 
Cabe aqui relacionar esse conceito proposto por Chaia para a produção contemporânea de arte à oportuna colocação de Nina Felshin (1995), ainda na década de 1990, na qual menciona o ativismo artístico como um híbrido. Suas raízes fincam-se também na arte conceitual da década de 1970, em que a arte não vale por apenas ser arte, mas está imbuída de um significado maior do que a obra dá a ver:

Com um pé no mundo da arte e o outro no mundo do ativismo político e organização comunitária, um híbrido marcante emergiu no meio dos anos 70, se expandiu nos anos 80 e está atingindo a massa crítica e se tornando institucionalizado nos anos 90 (FELSHIN, 1995, p. 9).

A autora chama este movimento cultural de "arte ativista", sendo uma confluência de impulsos estéticos, socio-políticos e tecnológicos na tentativa de mudança das barreiras e hierarquias que tradicionalmente definiam a cultura representada pelos que detêm o poder.

Felshin (1995) pontua, a partir do estudo de alguns artistas e grupos de arte estadunidenses, que os trabalhos da arte ativista pautam-se em elementos da cultura popular, da política, da tecnologia e dos meios de comunicação, além de movimentos artísticos, como a arte conceitual e 0 pós-modernismo artístico, dos anos 1960 até os dias atuais. 0 que é posto pela autora dirige-se também a estabelecer as bases do movimento cultural sobre o qual seu livro versa. Felshin, então, indica as raízes da arte ativista na década de 1960, momento em que, a partir do movimento dos direitos civis, da Guerra do Vietnã, do crescimento do movimento estudantil e do emergente movimento de contracultura, surgem questionamentos sobre a autoridade, os valores e as instituições do "sistema".

Ao reconstruir esse caminho histórico, Felshin (1995, p. 13-26) nota que alguns grupos ligados à política e à contracultura nos anos de 1960 e no começo da década de 1970, pelo uso criativo de estratégias de ativismo por meio de performances e de uso inteligente da mídia, anteciparam e refletiram algumas das práticas da arte ativista. Ainda que esses grupos não tivessem ligação alguma com 0 mundo da arte $\mathrm{e}$ não necessariamente se autoidentificassem como artistas, o uso criativo de imagens no espaço da publicidade e dos meios de comunicação e as performances por eles realizadas a fim de chamar a atenção da mídia já, de certo modo, prefiguravam o emprego de tais métodos pelos artistas ativistas que viriam a surgir com mais veemência a partir dos anos 1980.

Apesar de seu aparecimento no meio da década de 1970, apenas nos anos 1980 a arte ativista de fato ressurge em resposta às forças conservativas que dominaram tanto 0 mundo políico quanto o mundo da arte, ao aumento da incidência do ativismo na esquerda e na direita e à penetrante influência dos meios de comunicação (FELSHIN, 1995, p. 25).

Trazendo a crítica da arte conceitual ao objeto de arte e às estratégias estéticas formalistas, que valoravam mais o objeto e sua forma do que 0 contexto em que a arte era realizada e ao qual 
se destinava, Felshin (1995) aproxima o legado daquele movimento artístico à arte ativista. Para a autora, a arte conceitual ansiava estreitar as distâncias entre a arte e 0 público e entre a arte e a vida, urgindo pela necessidade de participação no "mundo real" e pela democratização das instituições existentes. Citando uma declaração feita em 1969 pelo artista Joseph Kosuth ${ }^{4}$ ao tratar da obra conceitual, Felshin (1995, p.19-20) parece querer resumir o trabalho artístico daquele movimento: "A nova obra não está conectada a um objeto valioso - ela é acessível para tantas quantas pessoas estiverem interessadas; ela não é decorativa - tendo nada a ver com arquitetura; ela pode ser levada para casa ou para um museu, mas não foi produzida sequer com isso em mente.

A arte ativista, como analisada por Felshin, parece ter tomado de empréstimo ou seguido as influências da arte conceitual no que se refere à abertura para as possibilidades estéticas mais inclusivas deste último movimento. A arte ativista parece ainda ter se aproveitado das proposições interdisciplinares do pós-modernismo artístico, pautado em discussões múltiplas e temas plurais. É necessário, no entanto, entender que essas influências não significam uma continuação num sentido evolutivo. Antes, deve haver a compreensão de que algo em comum une esses movimentos. Nesse sentido, Felshin (1995, p. 25-26) pondera:
Enquanto as metodologias e as intenções da arte conceitual, da arte pós-modernista politicamente engajada e da arte ativista diferem, e embora esses movimentos não devam ser considerados como movimentos sucessivos, uma linha comum os une. A crítica da arte conceitual às instituições de arte e às estratégias de estética formalistas, a crítica da arte pós-modernista à representação e as práticas da arte ativista são semelhantemente políticas; nisso, questionam as representações culturais dominantes e preocupam-se com as configurações de poder.

Remetendo a discussão agora, no entanto, aos temas múltiplos da arte pós-moderna, estes podem ser como críticas dos fundamentos da diferença, do mito da originalidade e das narrativas históricas, de acordo com Charles Harrison e Paul Wood (1998). Esses autores separam analiticamente as temáticas que têm guiado alguns trabalhos de arte pós-moderna, ainda que não haja um consenso sobre 0 term $0^{5}$ nem uma mudança significativa ou repentina entre a arte de uma década e a de outra, mesmo que um novo termo passe a ser utilizado para designá-la.

Nessa direção, a arte pós-moderna é pautada em um desdobramento da arte engajada dos anos 1970: "[...] a tendência a ignorar 0 tradicional foco radical na classe em favor de uma insistente concentração nas questões de gênero e, em menor medida, de raça" (WOOD, 1998, p. 238). A discussão em torno da questão 
do poder, engendrada nos trabalhos de Michel

Foucault em que tratava do controle, subjugação e regulação aplicados aos seres sociais pelos estados modernos, torna-se parte daquele desdobramento. Para Charles Harrison e Paul Wood (1998), as ideias sobre sexo e poder tornaram-se as temáticas centrais da prática cultural radical do período.

Nesse meio, surgem trabalhos de arte feminista, que reverberou as preocupações e os assuntos do movimento feminista dos anos 1960 e 1970, trazendo forma estética ao credo "o pessoal é político", fomentando a discussão da dimensão pública da experiência privada (FELSHIN, 1995, p. 18). Como citam Harrison e Wood (1998), as formas de opressão associadas às relações de gênero têm sido a principal preocupação da artista norteamericana Barbara Kruger. Tendo desenvolvido sua carreira como diretora de arte de revistas femininas para uma grande editora multinacional, Kruger aplicou essa experiência em trabalhos artísticos com forte conotação publicitária. Os autores pontuam que esses trabalhos de Kruger "[...] são marcados pela conjunção de uma imagem fotográfica básica, em geral de impressão monocromática, com um breve texto exortatório ou epigramático que funciona essencialmente com 0 slogan" (WOOD et al., 1998, p. 238).

\section{Considerações finais}

Então, a interferência cultural não é apenas sobre publicidade e consumismo, mas incorpora uma série de usos de produtos e imagens da mídia. 0 que essa prática faz é retrabalhar, reutilizar imagens e formatos preexistentes para criar novas imagens e conexões surpreendentes. Como Lessig (2004, p. 37) sugere, a experiência da mídia do século XXI não pode ser apenas do tipo "ler apenas", mas, "ler e escrever". Os praticantes da interferência temporariamente bloqueiam o fluxo de imagens - interferir na cultura - mas também improvisam e criam com essas novas imagens - interferem com a cultura, em um sentido musical. Em ambos os casos, a interferência cultural ilustra muitas das oportunidades e limitações do ambiente emergente da mídia "ler e escrever".

\section{Referências}

AGRE, P. E. Designing genres for new medias: Social, economic, and political contexts. In: JONES, S.

G. (Ed.). Cybersociety 2.0: Revisiting computermediated communication and community. Thousand Oaks, CA: Sage, 1998. p. 69-99.

ATTON, C. Alternative media. London: Sage, 2002.

ATTON, C. An alternative Internet. New York: Columbia University Press, 2004.

BIMBER, B.; FLANAGIN, A. J.; STOHL, C. Reconceptualizing contemporary media enviroment. Communcation Theory, v. 15, n. 4, p. 365-88, 2005. BORER, T. A. (Ed.). Media, mobilization and human rights: mediating suffering. London: Zed Books, 2012.

BRAHAN, S. Defining tactical media: An historical overview. New York: New Virtual Casebook Project, New York University [online], 2002. Disponível em < htto:// www.nyu.edu/fas/projects/vcb/case_911/reverberations/ brahan2.html> . Acesso em: 24 ago. 2013. 
CARDUCCI, V. Culture jamming: A sociological perspective. Journal of Consumer Culture, v. 6, n. I, p.116-138, 2006.

CHAIA, M. (Org.). Arte e política. Rio de Janeiro: Azougue Editorial, 2007.

CONDURU, R. Arte afro-brasileira. Belo Horizonte: Editora C/Arte, 2007.

COOPER, A. F.; TURCOTTE, J. F. Celebrity

diplomats as mobilizers? Celebrities and activism in a hypermediated time. In: BORER, T. A. (Ed.).

Media, mobilization and human rights: mediating suffering. London: Zed Books, 2012. p. 181-204.

CROWSTON, K.; WILLIAMS, M. Reproduced and emergent genres of communication on the World Wide Web. The Informational Society, v. 16, p. 201-15, 2000:

DEBORD, G.; WOLMAN, G. Methods of Detournement. In: KNABB, K. (Ed.). Situationist

International Anthology. Berkeley: Bureau of Public Secrets, 1981. p. 8-14.

DEBORD, GUY. The Society of Spectacle. Exeter: Rebel Press, 1987.

DERY, M. Culture jamming: Hacking, slashing and sniping in the empire signs. Open Magazine Pamphlet Series. Westfield, NJ [2010]. Disponível em $<$ http://www.markdery.com/archives/books/culture jamming/\#000005\#more > . Acesso em: 24 ago. 2013.

DERY, M. The Merry Pranksters and the art of hoax. New York Times, 23 dec. 1990. Disponível em < http://www. nytimes.com/1990/12/23/arts/the-merry-pranskstersand-the-art-of-the-hoax.html > . Acesso em: 24 ago. 2013.

DOWNING, J. et al. Radical Media: Rebellions communication and social movements. London: Sage, 2001.

DOWNING, J. et al. Social mobement theories and alternative media: An evaluation and critique.

Communication, Culture \& Critique, v. I, n. I, p. 40-50, 2008 .
FELSHIN, N. But Is It Art?: The Spirit of Art as Activism. Seattle: Bay Press, 1995.

\section{GARCIA, D.; LOVINK, G. The ABC of Tactical}

Media. [on-line]. Disponível em < http://subsol. c3.hu/subsol_2/contributors2/garcia-lovinktext. html> . Acesso em: 2 jun. 2013. (1997)

HAROLD, C. Pranking rethoric: 'Culture jamming' as media activism. Critical Studies in Media

Communication, v. 21, n. 3, p. 189-211, 2004.

HEBDRIGE, D. Suculture: The meaning of style. London: Routledge, 1979.

JENKINS, H. Quentin Tarantino's Star Wars? Digital Cinema, Media Convergence, and Participatory Culture. In: THORNURN, D.; JENKINS, H. Rethinking Media Change. Cambridge, MA: MIT Press, 2003. p. 281-312.

KESSLER, S. Amplifying individual impact: social media's emerging role in activism. In: BORER, T. A. (Ed.). Media, mobilization and human rights: mediating suffering. London: Zed Books, 2012. p. 205-215.

KNABB, K. (Ed.). Situationist International Anthology. Berkeley: Bureau of Public Secrets, 1981.

LESSIG, L. Free Culture. New York: Penguin, 2004.

LIEVROUW, L. A. Alternative and activist new media. Cambridge, UK: Polity Press, 2011.

\section{LIVINGSTONE, S. Making sense of television:}

The psychology of audience interpretation. London: Pergamon, 1990.

MARCUS, GREIL. Lipstick Traces: A Secret History of the Twentieth Century. London: Picador, 1989.

MARKOFF, J. Protesting the Big Brother lens, Little Brother turns an eye blind. New York Times, 7 0ct. 2002. Cr.

MCCAUGHEY, M.; AYERS, M. D. (Ed.). Cyberactivism: Online activism in theory and practice. New York: Routledge, 2003. 
MCQUAIL, D. McQuail's mass communication

theory. London: Sage, 2005.

MEIKLE, G. Future active: Media activism and the Internet. London: Routledge, 2002.

MONAHAN, T. Counter-surveillance as political intervention? Social Semiotics, v. 16, n. 4, p. 15-34, 2006.

NAIMARK, M. How to ZAP a camera: Using lasers to temporarilly neutralize camera sensors. 2002. Disponível em < http://www.naimark.net/projects/ zap/howto.html > Acesso em: 2 jul. 2013.

NEGATIVLAND. Fair Use: The Story of the Letter U and the Numeral 2. Concord, CA: Seeland, 1995.

SEGURADO, R. Por uma estética da reexistência na relação entre arte e política. In: CHAIA, M. (Org.). Arte e política. Rio de Janeiro: Azougue Editorial, 2007. p. 41-58.

STIMSON, B.; SHOLETTE, G. Introduction: Periodizing collectivism. In: STIMSON, B.; SHOLETTE, G. (Ed.).

Collectivism after Modernism: The Art of Social Imagination after 1945. Minneapolis: University of Minnesota Press, 2007. p.1-15.

THOMAS, D. Hacker culture. Minneapolis: University of Minneapolis Press, 2002.

VEGH, S. Classifying forms of online activism: The case of cyberprotests against the World Bank. In: MCCAUGHEY, M.; AYERS, M.D. (Ed.). Cyberactivism: Online activism in theory and practice. New York: Routledge, 2003. p.71-96.

VINHOSA, L. Obra de arte e experiência estética: arte contemporânea em questões. Rio de Janeiro: Apicuri, 2011.

WETTERGREN, A. Fun and laugher: Culture jamming and the emotional regime of late capitalism. Social Movement Studies, v. 8, n. I, p. 1-15, 2009.

W00D, Paul. Modernismo em disputa: a arte desde os anos quarenta. São Paulo: Cosac Naify, 1998. (Arte moderna: práticas e debates; 4 ) 


\section{Cultural jamming:} activism, media and art

Interferencia Cultural: el activismo, los medios de comunicación y el arte

\section{Abstract}

This article discusses a genre of activism in new media, the cultural jamming, setting out the main features of this practice of activism. We seek also to show how the cultural jamming is not restricted to a critique of consumerism or reworkings of advertising, but as it has also been used in the art field, especially at the interface of the politics and popular culture.

\section{Keywords}

Activism. New media. Cultural jamming. Artvism.

\section{Resumen}

Este artículo aborda un género del activismo en los nuevos medios, las interferencias culturales, exponiendo las principales características de esta práctica del activismo. Buscamos también muestrear cómo la interferencia cultural no se limita a una crítica del consumismo o reelaboraciones de la publicidad, pero, que también se ha utilizado en el campo del arte, especialmente en la interfaz de esta con la política y la cultura popular.

\section{Palabras-Clave}

Activismo. Nuevos medios de comunicación. Interferencia Cultural. Artivismo. 


\section{Expediente}

A revista E-Compós é a publicação científica em formato eletrônico da Associação Nacional dos Programas de Pós-Graduação em Comunicação (Compós). Lançada em 2004, tem como principal finalidade difundir a produção acadêmica de pesquisadores da área de Comunicação, inseridos em instituições do Brasil e do exterior.

\section{E-COMPÓS I www.e-compos.org.br I E-ISSN 1808-2599}

Revista da Associação Nacional dos Programas

de Pós-Graduação em Comunicacão.

Brasília, v.17, n.1, jan./abri. 2014.

A identificação das edições, a partir de 2008

passa a ser volume anual com três números.

\section{CONSELHO EDITORIAL}

Afonso Albuquerque, Universidade Federal Fluminense, Brasil Alberto Carlos Augusto Klein, Universidade Estadual de Londrina, Brasil Alex Fernando Teixeira Primo, Universidade Federal do Rio Grande do Sul, Brasil Ana Carolina Damboriarena Escosteguy, Pontifícia Universidade Católica do Rio Grande do Sul, Brasi

Ana Gruszynski, Universidade Federal do Rio Grande do Sul, Brasil Ana Silvia Lopes Davi Médola, Universidade Estadual Paulista, Brasil André Luiz Martins Lemos, Universidade Federal da Bahia, Brasi Ângela Freire Prysthon, Universidade Federal de Pernambuco, Brasil Antônio Fausto Neto, Universidade do Vale do Rio dos Sinos, Brasil Antonio Carlos Hohlfeldt, Pontifícia Universidade Católica do Rio Grande do Sul, Brasil Antonio Roberto Chiachiri Filho, Faculdade Cásper Líbero, Brasi Arlindo Ribeiro Machado, Universidade de São Paulo, Brasil Arthur Autran Franco de Sá Neto, Universidade Federal de São Carlos, Brasil Benjamim Picado, Universidade Federal Fluminense, Brasil César Geraldo Guimarães, Universidade Federal de Minas Gerais, Brasil Cristiane Freitas Gutfreind, Pontifícia Universidade Católica do Rio Grande do Sul, Brasil Denilson Lopes, Universidade Federal do Rio de Janeiro, Brasil Denize Correa Araujo, Universidade Tuiuti do Paraná, Brasi Edilson Cazeloto, Universidade Paulista , Brasil

Eduardo Vicente, Universidade de São Paulo, Brasil Eneus Trindade, Universidade de São Paulo, Brasil Erick Felinto de Oliveira, Universidade do Estado do Rio de Janeiro, Brasi Florence Dravet, Universidade Católica de Brasília, Brasil Gelson Santana, Universidade Anhembi/Morumbi, Brasi Gilson Vieira Monteiro, Universidade Federal do Amazonas, Brasil Gislene da Silva, Universidade Federal de Santa Catarina, Brasil Guillermo Orozco Gómez, Universidad de Guadalajara Gustavo Daudt Fischer, Universidade do Vale do Rio dos Sinos, Brasil Hector Ospina, Universidad de Manizales, Colômbia Herom Vargas, Universidade Municipal de São Caetano do Sul, Brasil Ieda Tucherman, Universidade Federal do Rio de Janeiro, Brasil Inês Vitorino, Universidade Federal do Ceará, Brasil Janice Caiafa, Universidade Federal do Rio de Janeiro, Brasil Jay David Bolter, Georgia Institute of Technology Jeder Silveira Janotti Junior, Universidade Federal de Pernambuco, Brasi João Freire Filho, Universidade Federal do Rio de Janeiro, Brasil John DH Downing, University of Texas at Austin, Estados Unidos
José Afonso da Silva Junior, Universidade Federal de Pernambuco, Brasil José Carlos Rodrigues, Pontifícia Universidade Católica do Rio de Janeiro, Brasil José Luiz Aidar Prado, Pontifícia Universidade Católica de São Paulo, Brasil José Luiz Warren Jardim Gomes Braga, Universidade do Vale do Rio dos Sinos, Brasil Juremir Machado da Silva, Pontifícia Universidade Católica do Rio Grande do Sul, Brasil Laan Mendes Barros, Universidade Metodista de São Paulo, Brasil Lance Strate, Fordham University, USA, Estados Unidos Lorraine Leu, University of Bristol, Grã-Bretanha Lucia Leão, Pontifícia Universidade Católica de São Paulo, Brasil Luciana Panke, Universidade Federal do Paraná, Brasil Luiz Claudio Martino, Universidade de Brasília, Brasil Malena Segura Contrera, Universidade Paulista, Brasil Márcio de Vasconcellos Serelle, Pontifícia Universidade Católica de Minas Gerais, Brasil Maria Aparecida Baccega, Universidade de São Paulo e Escola Superior de Propaganda e Marketing, Brasil Maria das Graças Pinto Coelho, Universidade Federal do Rio Grande do Norte, Brasil Maria Immacolata Vassallo de Lopes, Universidade de São Paulo, Brasil Maria Luiza Martins de Mendonça, Universidade Federal de Goiás, Brasil Mauro de Souza Ventura, Universidade Estadual Paulista, Brasil Mauro Pereira Porto, Tulane University, Estados Unidos Nilda Aparecida Jacks, Universidade Federal do Rio Grande do Sul, Brasil Paulo Roberto Gibaldi Vaz, Universidade Federal do Rio de Janeiro, Brasil Potiguara Mendes Silveira Jr, Universidade Federal de Juiz de Fora, Brasil Renato Cordeiro Gomes, Pontifícia Universidade Católica do Rio de Janeiro, Brasil Robert K Logan, University of Toronto, Canadá

Ronaldo George Helal, Universidade do Estado do Rio de Janeiro, Brasil Rosana de Lima Soares, Universidade de São Paulo, Brasil Rose Melo Rocha, Escola Superior de Propaganda e Marketing, Brasil Rossana Reguillo, Instituto de Estudos Superiores do Ocidente, Mexico Rousiley Celi Moreira Maia, Universidade Federal de Minas Gerais, Brasi Sebastião Carlos de Morais Squirra, Universidade Metodista de São Paulo, Brasil Sebastião Guilherme Albano da Costa, Universidade Federal do Rio Grande do Norte, Brasil

Simone Maria Andrade Pereira de Sá, Universidade Federal Fluminense, Brasi Tiago Quiroga Fausto Neto, Universidade de Brasília, Brasil Suzete Venturelli, Universidade de Brasília, Brasil Valerio Fuenzalida Fernández, Puc-Chile, Chile Veneza Mayora Ronsini, Universidade Federal de Santa Maria, Brasil Vera Regina Veiga França, Universidade Federal de Minas Gerais, Brasil

\section{COMISSÃO EDITORIAL}

Cristiane Freitas Gutfreind I Pontifícia Universidade Católica do Rio Grande do Sul, Brasil Irene Machado I Universidade de São Paulo, Brasil

Jorge Cardoso Filho I Universidade Federal do Reconcavo da Bahia, Brasil / Universidade Federal da Bahia, Brasil

CONSULTORES AD HOC

Adriana Amaral, Universidade do Vale do Rio dos Sinos, Brasil

Alexandre Rocha da Silva, Universidade Federal do Rio Grande do Sul, Brasi Arthur Ituassu, Pontifícia Universidade Católica do Rio de Janeiro, Brasil Bruno Souza Leal, Universidade Federal de Minas Gerais, Brasil Elizabeth Bastos Duarte, Universidade Federal de Santa Maria, Brasil Francisco Paulo Jamil Marques, Universidade Federal do Ceará, Brasi Maurício Lissovsky, Universidade Federal do Rio de Janeiro, Brasil Suzana Kilpp, Universidade do Vale do Rio dos Sinos, Brasil Vander Casaqui, Escola Superior de Propaganda e Marketing, Brasil

EDIÇÃO DE TEXTO E RESUMOS I Susane Barros SECRETÁRIA EXECUTIVA I Helena Stigger EDITORAÇÃo ELETRÔNICA I Roka Estúdio
COMPÓS I www.compos.org.br

Associação Nacional dos Programas de Pós-Graduação em Comunicação

Presidente

Eduardo Morettin

Universidade de São Paulo, Brasil

eduardomorettin@usp.br

Vice-presidente

Inês Vitorino

Universidade Federal do Ceará, Brasil

ines@ufc.br

Secretária-Geral

Gislene da Silva

Universidade Federal de Santa Catarina, Brasil

gislenedasilva@gmail.com 